IRA-International Journal of Education \& Multidisciplinary Studies ISSN 2455-2526; Vol.06, Issue 01 (2017) Pg. no. $80-83$

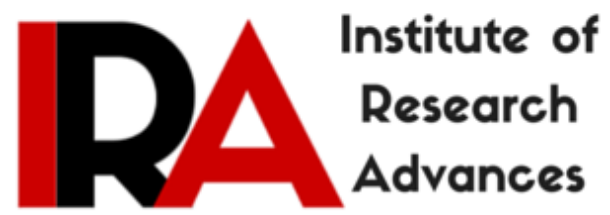

\title{
Geriatric Burns- A Study- In a Tertiary Burn Care Centre
}

\author{
Dr. Angeline Selvaraj (M.S., M.Ch.) ${ }^{1}$ \\ Associate Professor, \\ Dr. G Karthikeyan (M.S., M.Ch.) ${ }^{2}$ \\ Associate Professor, \\ Dr. Nirmala Ponnambalam (M.S., M.Ch.) ${ }^{3}$ \\ Professor \& HOD. \\ ${ }^{1,2,3}$ Department of Burns Plastic \& Reconstructive Surgery, Govt. Kilpauk Medical \\ College Hospital, Chennai, India.
}

Type of Review: Peer Reviewed.

DOI: http://dx.doi.org/10.21013/jems.v6.n1.p5

\section{How to cite this paper:}

Selvaraj, A., Karthikeyan, G., \& Ponnambalam, N. (2017). Geriatric Burns- A Study- In a Tertiary Burn Care Centre. IRA International Journal of Education and Multidisciplinary Studies (ISSN 2455-2526), 6(1), 80-83. doi:http://dx.doi.org/10.21013/jems.v6.n1.p5

(C) Institute of Research Advances

(cc) EY-NC

This work is licensed under a Creative Commons Attribution-Non Commercial 4.0 International License subject to proper citation to the publication source of the work.

Disclaimer: The scholarly papers as reviewed and published by the Institute of Research Advances (IRA) are the views and opinions of their respective authors and are not the views or opinions of the IRA. The IRA disclaims of any harm or loss caused due to the published content to any party. 


ABSTRACT
With increased life span there is an increase in ageing population, who are brought for management
of burn injuries to the tertiary burn centre in Government Kilpauk Medical College Hospital in
Chennai, Tamilnadu. The special care needed in managing these patients have been analyzed and
presented in this study.

Key words: Geriatric Burns, Tertiary Burn Care Centre.

Abbreviations Used: COPD-Chronic Obstructive Pulmonary Disease, TBSA- Total Burn Surface Area

Materials and Methods: This is a retrospective study done in the tertiary burn care centre at Kilpauk Medical College Hospital from January 2015 to December 2015. Out of the 1742 admissions, geriatric patients (65 years and above) were 104. The records of these patients were analyzed for the type of burn, etiology of burn, area of body surface that was involved, co-morbid conditions and the final outcome of these patients.

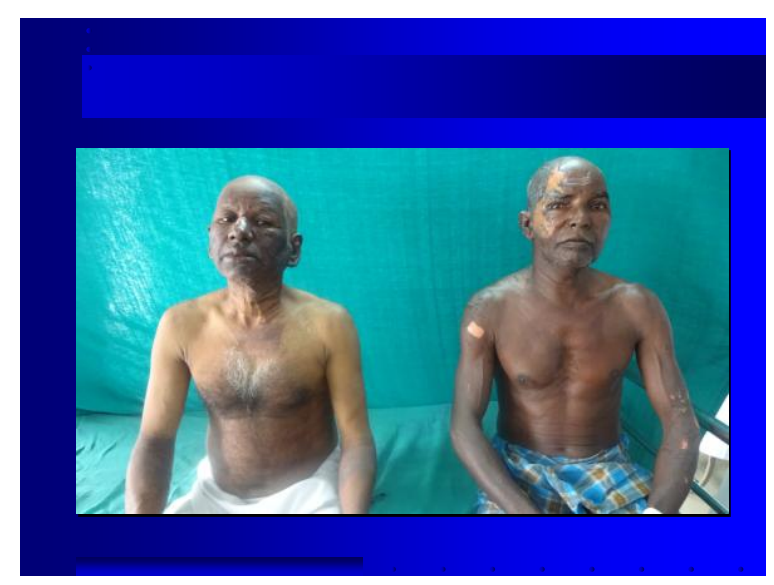

Geriatric patients- above 65 years of age- were studied in this group. Most of these patients have a higher incidence of co- morbidities like diabetes mellitus, coronary artery disease, cerebrovascular accidents and respiratory disorders. ${ }^{(4)}$ Their physiological reserve is low. They have decreased cardio pulmonary reserve and usually suffer from COPD, atherosclerosis, and impaired nutrition. The skin shows signs of aging as evidenced by thinning of dermis \& atrophy of skin appendages. The lean body mass is decreased.

Burn care in the geriatric patients: ${ }^{(5)}$ Geriatric patients sustain burns, which may be accidental or intentional. Burns may be due to flame, scalds, electricity or chemicals. Usual protocol is to resuscitate the burn victim by following modified Parkland formula of $3 \mathrm{ml} /$ percentage of Burn Surface Area/ $\mathrm{kg}$ body weight. In the geriatric age group, fluid requirement has to be titrated according to burn depth, inhalation injury, and cardiac or renal parameters. These patients may require ventilator support as their pulmonary reserve is low and they are more prone to fatigue. The reduced lean body mass results in decreased body protein level. This leads to immune suppression, organ dysfunction and impaired wound healing. Geriatric patients have hyper metabolic response which can persist from 9 to 12 months, leading to increased protein catabolism, increased daily protein and nutritional requirements. ${ }^{(3)}$ Nutritional supplementation with protein hydrolysate, peptide and amino acids can ease gut absorption of proteins, as opposed to whole proteins. 


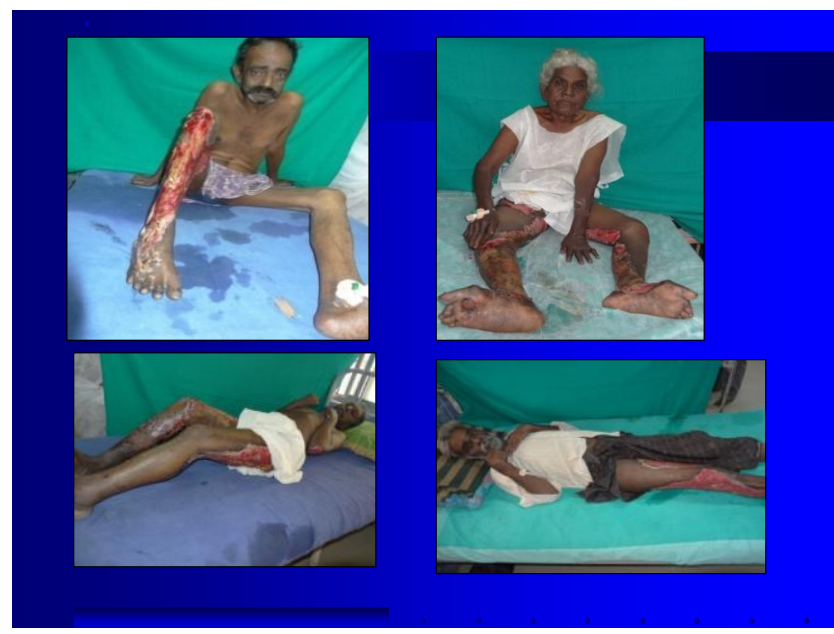

Infection of the burn wound and infection of respiratory or urinary system has to be dealt with aggressive use of appropriate antibiotics, taking into consideration the renal and hepatic status of the patient. To control pneumonitis, chest physiotherapy and bronchodilators are required. Postural drainage can help in bringing out sputum.

Burn wounds are deeper in geriatric patients due to the nature of their skin. Their skin is thin with decreased vascularity, reduced collagen and cellularity. Burn wounds are managed with dressings, collagen or skin grafts. Early skin cover by skin grafts gives a better outcome.

Team Approach: The burn team involved in managing geriatric patient consists of intensivist, nephrologist, cardiologist, neurologist, urologist, psychiatrist, physiotherapist, nursing personnel and counselor.

Observation: Geriatric burn constitutes to about 6\% of admissions in the burn unit. Among the 1742 inpatients, there were 104 geriatric patients.

There was a female preponderance, as 67 patients were female and 37 were male.
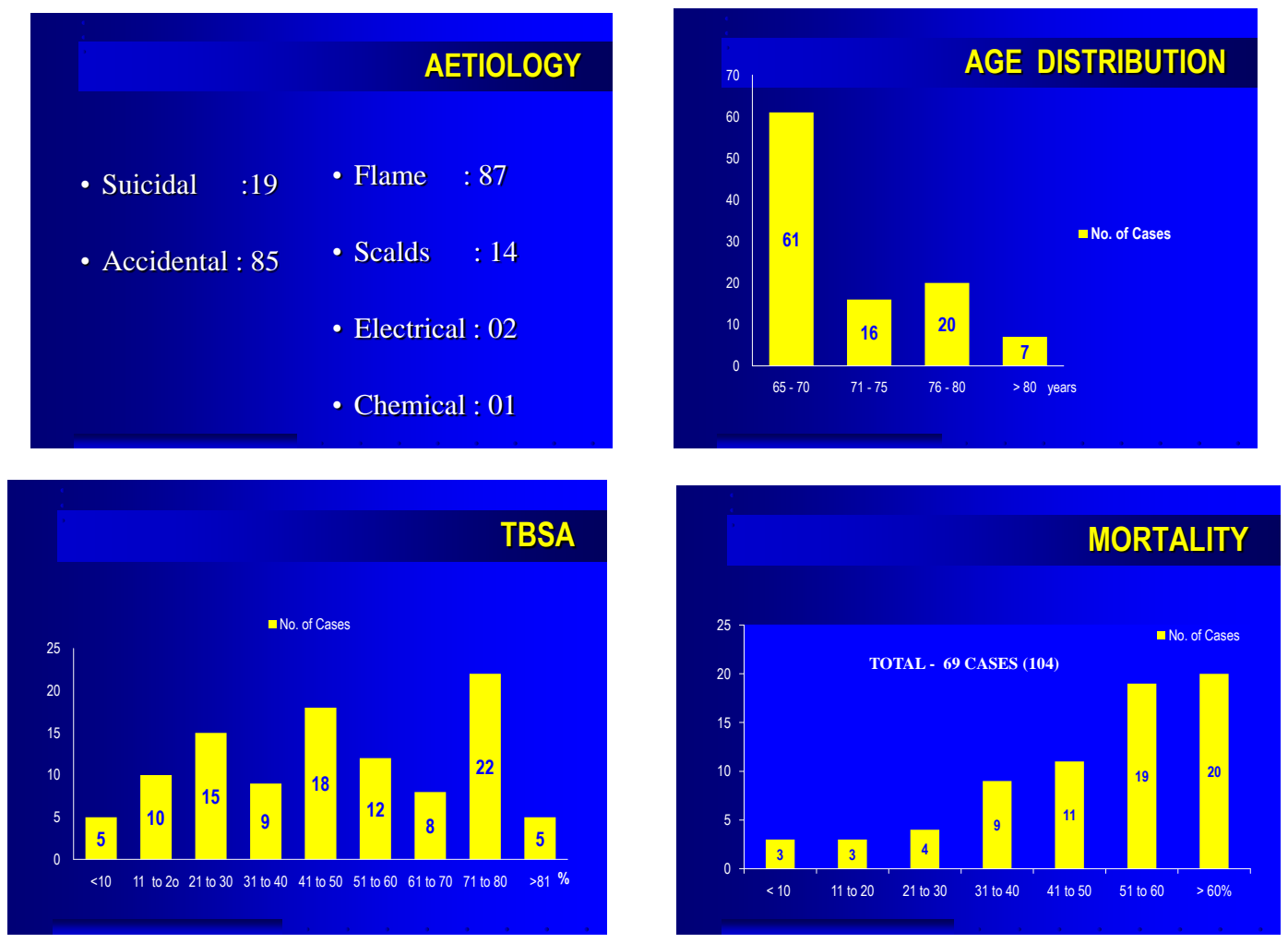
There was a higher distribution of patients in 65 to 70 years (61 patients). 71 to 75 year age group had 16 patients and 75 to 80 years group had 20 patients and more than 81 years group had only 7 patients.

Most burn patients in the geriatric age group had higher Burn Surface Area of burns. Less than $10 \%$ Burn Surface Area burn was seen in only 5 patients. 11 to $20 \%$ Burn Surface Area in 10 patients, 21 to $30 \%$ Burn Surface Area in 15 patients, 31 to $40 \%$ Burn Surface Area in 9 patients, 41 to $50 \% 18$ patients, 51 to $60 \%$ in 12 patients, 61 to $70 \%$ in 8 patients, 71 to $80 \%$ in 22 patients and more than $80 \%$ Burn Surface Area burn in 5 patients.

According to the history, most burns were accidental. 85 patients had given history of accident and 19 were self-inflicted. Flame burn predominated as the etiology, with 87 patients in this group, 14 patients had scalds, 2 patients sustained electrical burn and 1 had burn due to chemical contact. Outcome of the geriatric burn victims showed high incidence of mortality ${ }^{(2)(6)}$.

69 geriatric patients in this study died and $66 \%$ mortality was observed. Mortality increased with increase in the percentage burn area involved. There were 3 deaths in less than $10 \%$ Burn Surface Area. It was noted that death in the lower Burn Surface Area percentage group was due to associated co-morbidities.

Conclusion: Our study showed that the incidence of geriatric burn was higher in females. Flame burns due to accidents were more common and mortality was $66 \%$ due to associated co morbid conditions. Finally a note of concern is that these patients do not voice whether they were abused, as they fear reprisal from the caretakers/relatives, on whom they are dependent.

\section{Reference:}

1. Demling RH: Elderly Burn Patients: J. Burn Rehabilitation. 2005

2. Hunt JL, Purdue GF, The Elderly Burn Patient. American J. Surgery 1992 Nov, 164(5) 472-6

3. Jeschke MG, et al. Burn Size Determines the Inflammatory and Hyper-Metabolic Response. Critical Care, 2007:11:R90

4. Lundgren RS, et al. Influence of Comorbidities and Age on Outcome Following Burn Injury in Older Adults. Journal of Burn Care \& Research 2009:30:307-14

5. Pruitt B In Epidemiological, Demographic and Outcome Characteristics of Burn Injury in Total Burn Care. Herndon DN, Author, Total Burn Care, 2007.pp14-32

6. Mc Gill V., Kowal-Vern A, Gamelli RL. Outcome for Older Burn Patients. Arch.Surg2000;135;320-5. 